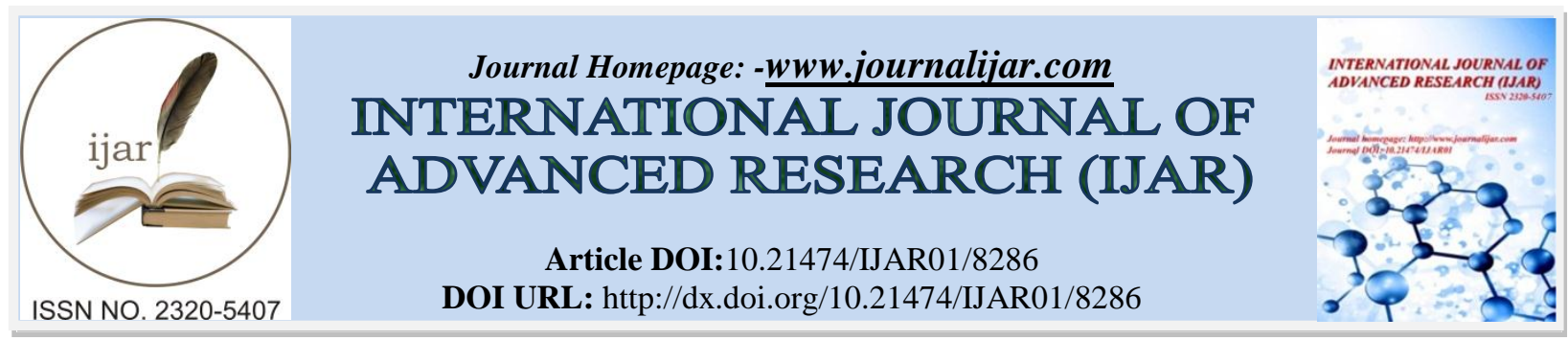

RESEARCH ARTICLE

\title{
ANTIMALARIAL ACTIVITY OF COMBINATIONS OF PLANTS USED IN THE TREATMENT OF MALARIA IN THE CHILD AND THE PREGNANT WOMAN.
}

\section{Sossa p. Atchade ${ }^{3}$, Karim Tuo ${ }^{1}$, Seinde e. Medoatinsa ${ }^{2,4}$, Andre o. Toure ${ }^{1}$, Sylvain Beourou ${ }^{1}$, Cokou p. Agbangnan dossa ${ }^{4}$, Maximin Senou ${ }^{2}$ and Mireille Dosso ${ }^{1}$.}

1. Unite de paludologie de l'institut pasteur de cote-d'ivoire (upal/ipci).

2. Laboratoire de biologie experimentale et clinique, ecole nationale superieure des biosciences et biotechnologies appliquees labec/ensbba/unstim.

3. Departement de genie de biologie humaine, ecole polytechnique d'abomey-calavi (gbh/epac/uac).

4. Laboratoire d'etude et de recherche en chimie appliquee, ecole polytechnique d'abomey-calavi, universite d'abomey-calavi (lerca/epac/uac).

5. Laboratoire d'enzymologie et de biochimie des proteines, faculte des sciences et techniques (lebp/fast/uac).

\section{Manuscript Info}

Manuscript History

Received: 20 October 2018

Final Accepted: 22 November 2018

Published: December 2018

Key words:-

Malaria, resistance, flora, metabolites, hemolysis.

\section{Abstract}

This study aimed to contribute to the fight against malaria by evaluating the anti-malarial potential of combinations of plants used in traditional medicine to treat malaria in Benin. Antiplasmodial activity was evaluated by the Sybr green method on clinical isolates and the K1 strain (chloroquine and pyrimethamine resistant) of Plasmodium falciparum while the DPPH trapping test was used to determine the anti-radical activity. Acute toxicity and anti-pyretic test were performed in vivo on Wistar rats. Secondary metabolites were identified by tube characterization tests and confirmed by spectrophotometric assay. The aqueous decoctions of the recipes are not-hemolytic (percentage of hemolysis $<5 \%$ ) and endowed with anti-plasmodial activity (Child: IC50<15 $\mu \mathrm{g} / \mathrm{mL}$ ). Combinations of plants are not toxic (LD50 $>5 \mathrm{~g} / \mathrm{kg}$ ), rich in secondary metabolites and contain anti-radical and anti-pyretic molecules, but only the aqueous decoction of the child's recipe showed good anti-radical activity $\left(\mathrm{IC}_{50}=0.095 \mu \mathrm{g} / \mathrm{ml}\right)$ and anti-pyretic comparable to that of aspirin (reference molecule). The different activities observed would be due to the synergistic effect of the secondary metabolites (phenolic compounds, alkaloids, sterols, terpenes) present in the investigated recipes. The toxicological and clinical trials will allow us to bring to market anti-malarial and antipyretic drugs.

Copy Right, IJAR, 2017,. All rights reserved.

\section{Introduction:-}

Malaria is a parasitic disease caused by the presence and proliferation in the body of a protozoan of the genus Plasmodium1. It is transmitted to humans by the bite of a female mosquito, the Anopheles2. Young children, pregnant women, no-immune travelers from malaria-free areas are particularly vulnerable to the disease when they become infected. In 2017, there are an estimated 219 million cases of malaria. 92\% of the cases occurred in Sub-

Corresponding Author:-Sossa p. Atchade.

Address:-Unite de Paludologie de l'Institut Pasteur de Cote-d'Ivoire (UPAL/IPCI). 
Saharan Africa, resulting in 435,000 deaths, of which $61 \%$ are children under five years 3 . West African country, Benin is not spared. Malaria is the leading cause of hospitalization and death for both the general population and the target population4. Despite the current therapeutic arsenal for the treatment of malaria, the development of resistance of Plasmodium to treatment5 reinforces the urgent need to find new natural antimalarials that are less expensive and without major consequences for human health and the environment. Malaria causes tropical pathologies treated by plants. According to the World Health Organization (WHO), in some countries in Asia, Africa and Latin America, $80 \%$ of the population depend on traditional medicine because of lack of access to modern medicine, inaccessibility to drugs despite the advent of generic drugs and socio-cultural behaviors of these populations6. Unfortunately, these plants are not very often subject to pharmacognosic and toxicological studies. The bioactive and toxic principles of plants are little known. There is therefore a permanent danger with regard to the therapeutic doses on the one hand and the lethal doses on the other hand. In order to contribute to the sanitary safety of the beninese population and of those living in malaria-endemic areas, the present work has been initiated and aims to contribute to the fight against malaria by evaluating the anti-malarial potential of the combinations of plants used in traditional medicine to treat malaria in a lake environment in southern Benin.

\section{Material:-}

\section{Vegetable material:-}

Vegetable material was obtained following an ethnobotanical survey carried out on the lacustrine population of southern Benin. The number of plants per recipe varies from 6 (child) to 11 (pregnant woman). The plant material was collected and identified at the National Herbarium of Benin before being dried at laboratory temperature $\left(25^{\circ}\right.$ C) until it's mass stabilization and finally pulverized by an electric grinder (Brand RETSCH, Type SM 100).

\begin{tabular}{|c|c|}
\hline \multicolumn{2}{|c|}{ Pregnant woman } \\
\hline Plant species & families \\
\hline Hibiscussurrattensis & Malvaceae \\
\hline Pavettacrassipes & Rubiaceae \\
\hline Cajanuspigeon & Papilinoideae \\
\hline Dissotisrotundifolia & Melastomataceae \\
\hline Cymbopogoncitratus & Poaceae \\
\hline Pleiocarpapycnantha & Apocynaceae \\
\hline Spathodeacampanulata & Bignoniaceae \\
\hline Cymbopogongiganteus & Poaceae \\
\hline Phymatodesscolopandria & Polypodiaceae \\
\hline Dichapetalummadagascariensis & Dichapetalaceae \\
\hline Newbouldialaevis & Bignoniaceae \\
\hline
\end{tabular}

\begin{tabular}{|c|c|}
\hline \multicolumn{2}{|c|}{ Child } \\
\hline Plant species & families \\
\hline Pteleopsissuberosa & Combretaceae \\
\hline Waltheriaindica & Sterculiaceae \\
\hline Lippiamultiflora & Verbenaceae \\
\hline Combretumindicum & Combretaceae \\
\hline Ehretiacymosa & Boraginaceae \\
\hline Hyptissuaveolens & Lamiaceae \\
\hline
\end{tabular}

\section{Animal material:-}

In this study we used: Wistar rats, the K1 strain of Plasmodium falciparum (resistant to chloroquine and pyrimethamine), clinical isolates of Plasmodium falciparumobtained at the Anonkoua-kouté Community Based Health and Urban Training Program in Abobo, a peripheral district of Abidjan, Ivory-Coast.

\section{Laboratory equipment}

Among the laboratory equipment used, we can mention: the spectrophotometer (4049LKB, Biochrom, Cambridge, CB4 4FJ Angland), the electronic thermometer equipped with sonde (Dostmann electronic $\mathrm{GmnH}$ ), the centrifuge 
(Eppendorf, Centrifuge 5702), the hood with laminar flow (ESCO Airstream Class II), optical microscope, incubator (Heratherm, Thermo Scientific), spectrofluorometer (Spectra Max GEMINI XPS).

\section{Reagents}

Beer yeast, sodium chloride (Sigma-Aldrich), dinitrophenylhydrazine (Sigma-Aldrich), RPMI 1640 (eurobioAbCys), albumax II, L-glutamine (eurobioAbCys), hypoxanthine (eurobioAbCys), SYBR Green, gentamicin (Sigma-Aldrich), TritonX-100 (Sigma-Aldrich), DPPH, sulfuric vanillin, aluminum trichloride, FolinCiocalteu reagent are the reagents used during the differents manipulations.

\section{Methodology:-}

\section{Phytochemical Screening:-}

The determination of secondary metabolites has been made by differential coloring and precipitation reactions of the main families of chemical compounds in plants. Thus, the search for sterols and terpenes was done by the Liebermann test7. The characterization of phenolic compounds was made by the reaction with ferric perchloride8. Flavonoids were identified by the cyanidin reaction9. The compounds belonging to the group of tannins were highlighted by the reaction of Stiasny10. The search for saponosides is based on their aphrogenic property. The alkaloid search was done using Mayer and Bouchardat reagents.

\section{Determination of phenolic compounds:-}

Total polyphenols: The method of determination of total polyphenols consisted to use a mixture of phosphotungsticand phosphomolybdic acid which was reduced during the oxidation of phenols in the mixture oftungsten blue oxide and molybden11. The filtrates hydro-ethanolic macerated (water/ethanol: 30/70) and aqueous decoction were used.The absorbance was measured by a spectrophotometer (JENWAY50/60 Hz) at $765 \mathrm{~nm}$. Gallic acid was used as reference and the total polyphenol content in the extract was expressedin mg of gallic acid equivalents per gram of dry matter.

\section{Total flavonoids:-}

The method of aluminum trichloride $(\mathrm{AlCl} 3)$ was used to quantify the total flavonoids. Thistechnique was based on the formation of the aluminum-flavonoids complex that had a maximum absorption at500 nm12.

\section{Condensed tannins:-}

condensed tannins quantification was achieved by using the method of vanillin sulfuric13.The principle of this assay was based on the binding of vanillin aldehyde group on the carbon in position 6 ofthe ring of the catechol to form a red colored complex chromophore which absorbs at $510 \mathrm{~nm}$.

\section{Determination of anti-radical activity:-}

This activity of each extract was assessed by measuring free-radical scavenging activity via the decoloration of a solution of the free radical 1,1-diphenyl-2-picrylhydrazyl (DPPH). The absorbance (A) of DPPH was mesured with a spectrophotometer at $517 \mathrm{~nm} 14$, and the radical scavenging activity of each sample was expressed as percentage inhibition:

$\%$ inhibition $=([$ Acontrol - Asample $] /$ Acontrol $) \times 100$

\section{Acute toxicity:-}

The rats were fasted for 12 hours. They were divided into five lots ( 3 rats per batch) including a control group receiving distilled water. The extracts were administered according to the body weight of the rats, by gavage at a dose of $5 \mathrm{~g} / \mathrm{kg}$ of animal body weight. After gavage of extracts and distilled water, the rats were observed immediately then every 30 minutes, for three hours, the first day and once daily for 14 days. During this period, the rats were weighed and symptomatic disorders (agitation, lack of appetite, motor difficulty, salivation, diarrhea, convulsion and dyspnoea) were sought 15.

\section{Antipyretic test:-}

Since malaria is a feverish disease, this test allowed us to evaluate the antipyretic potential of the recipes. The test was performed at a dose of $500 \mathrm{mg} / \mathrm{kg}$ of rat body weight. This test was conducted according to the methodology used by Dosseh and collaborators in 201416. 


\section{Antiplasmodial test in vitro and ex vivo:-}

In vitro tests on Plasmodium require permanent access to a strain maintained daily. The continuous in vitro culture technique of P. falciparum used in our assays is derived from that developed by Trager and Jensen (1976)17. The culture medium is RPMI 1640 (SIGMA®) enriched with 5\% of albumax and L-glutamine (essential amino acid). The healthy red blood cells used are group $\mathrm{O}$, for good serum compatibility and positive Rh. Inhibition of erythrocyte schizogony (P. falciparum) is measured using the SYBR Green method18-20. The range of concentrations of the extracts tested varies from 100 to $1.56 \mu \mathrm{g} / \mathrm{mL}$. They were tested in duplicate. The IC50 (extract concentration that inhibits parasite growth by 50\%) were determined graphically using the Worldwide Antimalarial Resistance Network (WWARN) IVART software (In Vitro Analysis and Reporting Tool).

\section{Hemolysis test in vitro:-}

The purpose of this test is to determine whether the anti-plasmodial activity observed in vitro is not related to a simple lysis of red blood cells. Indeed, if the sample causes hemolysis, the parasite can't develop properly and thus the measured anti-plasmodial activity would not reflect the action of the extract on Plasmodium. The methodology is that used by Tuo in 201521. The following formula is used to calculate the percentage of hemolysis:

$\%$ hemolysis $=[($ Asample tested - Anegative control $) /($ Apositive control - Anegative control $)] \mathrm{x} 100$

$\mathrm{A}$ is the Absorbance at $550 \mathrm{~nm}$

\section{Results and Discussion:-}

\section{Phytochemistry:-}

The table1 below shows the different metabolites identified during the phytochemical screening.

Tableau 1:-Metabolites identified

\begin{tabular}{|l|c|c|}
\hline & Child & Pregnant woman \\
\hline Saponoside & + & + \\
\hline Reducing sugar & + & + \\
\hline Phenolic compound & + & + \\
\hline Flavonoid & + & + \\
\hline Anthocyanin & + & + \\
\hline Condensed tannin & + & + \\
\hline Gallic tannin & + & + \\
\hline Leucoanthocyane & + & + \\
\hline Alkaloid & - & - \\
\hline Quinone & - & \\
\hline Mucilage & + & \\
\hline Sterols and terpenes & + \\
\hline
\end{tabular}

+ : Presence ;- : Absence

We note the presence of saponosides, reducing sugars, flavonoids, anthocyanins, tannins, alkaloids, steroles and terpenes in the recipes. On the other hand, mucilages and quinones are absent. The leucoanthocyanins were found only in the recipe of the child. All the investigated recipes are rich in secondary metabolites. The presence of alkaloids, flavonoids, sterols and terpenes recognized for their anti-plasmodial property22-24 in recipes would justify their use in the treatment of malaria in Benin.

\section{Extraction yield:-}

Table 2:-shows the yields of extractions obtained.

Tableau 2:-Extraction yield (\%)

\begin{tabular}{|l|l|c|}
\hline & Child & Pregnant woman \\
\hline Aqueous decocted & 24.74 & 18.08 \\
\hline Macerated hydro-ethanolic & 19.18 & 17.81 \\
\hline
\end{tabular}


The metabolites contained in the combinations of plants investigated, are more extractable by hot water than cold hydro-ethanolic mixture. The main form of use of recipes by the population (decocted) is therefore the best from the point of view of extraction efficiency of the metabolites. The increase in temperature during the decoction has a positive influence on the extraction yield by promoting the diffusion and solubility of the extracted substances. Some authors such as Penchev et al., 201025; Jokić et al., 201026; Agbangnan et al., 201212 reached the same conclusion.

\section{Phenolic content:-}

Figure 1 shows the phenolic compound content of aqueous decocted and hydro-ethanolic macerated of the plant combinations that are the subject of this study.

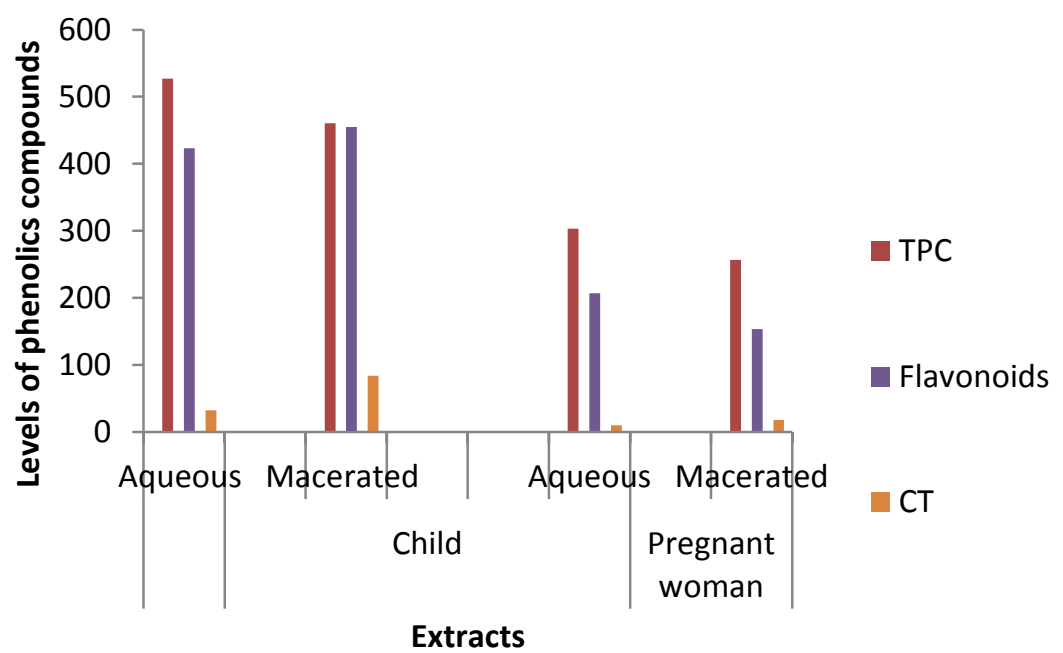

TPC:-Total Phenolics Compounds; CT: Condensed Tannins

Figure 1:-Levels of phenolics compounds

Aqueous decocteds are richer in total phenolics compounds than hydro-ethanolic macerated, which confirms the extraction yield obtained. The combination of plants used in the treatment of malaria in child is richer in total phenolic compounds, flavonoids and condensed tannins as used for pregnant woman.

Anti-radical activity

The IC50 values obtained following the DPPH trapping test are presented in Table 3.

Tableau 3:-IC50

\begin{tabular}{|l|c|c|c|}
\hline & Aqueousdecocted & \multicolumn{2}{|c|}{ Hydro-ethanolic macerated } \\
\hline Child & 0.095 & 0.350 \\
\hline Pregnant woman & 0.320 & 0.400 \\
\hline BHA & \multicolumn{3}{|c|}{0.090} \\
\hline Quercetin & 0.100 & \\
\hline
\end{tabular}

The evaluation of the anti-radical property of our extracts shows that they have constituents which discolour the solution of the DPPH which turns from purple to yellow. The anti-radical activity of each of the extracts on the free radical DPPH is expressed as the concentration of the substrate which inhibits 50\% of the DPPH radical (IC50). The anti-radical ability of an extract is considerable when its IC50 is low.The decoction of child recipe was very effective with regard to trapping of DPPH compared to other extracts and reference antioxidants (quercetin: 0.1 $\mathrm{mg} / \mathrm{mL}$; BHA $0.09 \mathrm{mg} / \mathrm{mL}$ ) used during this study.

Acute toxicity:-

At the end of the acute toxicity evaluation of the extracts, we did not observe any symptomatic disorder (restlessness, lack of appetite, motor difficulty and dyspnea) or recorded no deaths in the rank of the rats subjected to 
this study. It appears that the investigated extracts are practically not-toxic with a lethal dose of 50 (LD50) greater than $5 \mathrm{~g} / \mathrm{kg} 27$. The weekly weighings carried out throughout the duration of the experiment (14 days) made it possible to follow the weight evolution of the treated animals and those controls. Table 4 shows the average body weight of the rats throughout the acute toxicity test.

Tableau 4:-Body weight of rats

\begin{tabular}{|l|c|c|c|}
\hline & D0 & J7 & J14 \\
\hline Witnesses & $192.60 \pm 14.01$ & $199.70 \pm 16.10$ & $204.70 \pm 19.88$ \\
\hline Childaq & $215.30 \pm 8.37$ & $219.70 \pm 11.05$ & $215.70 \pm 11.78$ \\
\hline Enfhet & $254.70 \pm 1.76$ & $253.00 \pm 4.73$ & $256.70 \pm 4.67$ \\
\hline Womanaq & $148.00 \pm 2.00$ & $148.30 \pm 1.76$ & $143.70 \pm 1.20$ \\
\hline Womanhet & $162.70 \pm 4.67$ & $163.70 \pm 4.70$ & $163.30 \pm 3.84$ \\
\hline
\end{tabular}

Aq: Aqueous decocted ; Het: Hydro-ethanolic macerated

During the first week, we noted a weight gain in the rats fed with distilled water, the aqueous decoctions of the recipes of the child, the pregnant woman, while in the second week we observe a loss of weight in rats taking aqueous decocts from the recipes of the child, the pregnant woman. Nevertheless, the ANOVA test shows that this difference is not significant at the $5 \%$ for the different groups. Thus, our extracts, "per os" do not affect the evolution of body weight of rats. The change in body weight being an indicator of the adverse effects of chemical compounds28, we can therefore conclude that the extracts are not toxic and don't have single dose adverse effects at $5 \mathrm{~g} / \mathrm{kg}$ body weight orally. The result obtained demonstrates the safety and employment security of the investigated recipes.

\section{Antipyretic test:-}

Table 5 presents the results obtained following the evaluation of the antipyretic activity of the extracts investigated in vivo.

Tableau 5:-Rectal temperatures of rats during the anti-pyretic test

\begin{tabular}{|l|c|c|c|c|c|c|}
\hline \multirow{2}{*}{ Treatment } & \multicolumn{3}{|c|}{ Temperatures } \\
\cline { 2 - 6 } & T0 & T1 & T2 & T3 & T4 & T5 \\
\hline Negative control & $37.50 \pm$ & $37.87 \pm$ & $37.87 \pm 0.30$ & $37.40 \pm$ & $37.23 \pm$ & $37.23 \pm$ \\
& 0.10 & 0.27 & & 0.35 & 0.35 & 0.35 \\
\hline Positive control & $36.93 \pm$ & $37.57 \pm$ & $37.17 \pm 0.17$ & $37.00 \pm$ & $\mathbf{3 6 . 6 7} \pm$ & $\mathbf{3 6 . 0 3} \pm$ \\
& 0.32 & 0.14 & & 0.23 & $\mathbf{0 . 3 5}$ & $\mathbf{0 . 2 5} *$ \\
\hline Child Het & $37.53 \pm$ & $37.87 \pm$ & $38.03 \pm 0.52$ & $37.67 \pm$ & $37.23 \pm$ & $37.20 \pm$ \\
& 0.07 & 0.39 & & 0.35 & 0.18 & 0.20 \\
\hline Child aq & $37.17 \pm$ & $37.13 \pm$ & $36.77 \pm 0.48$ & $\mathbf{3 6 . 4 7} \pm$ & $\mathbf{3 6 . 2 3} \pm$ & $\mathbf{3 6 . 0 7} \pm$ \\
& 0.03 & 0.18 & & $\mathbf{0 . 6 1}$ & $\mathbf{0 . 6 4}$ & $\mathbf{0 . 4 8} *$ \\
\hline Pregnant woman Het & $37.20 \pm$ & $37.53 \pm$ & $37.40 \pm 0.15$ & $37.30 \pm$ & $37.17 \pm$ & $36.87 \pm$ \\
& 0.25 & 0.09 & & 0.12 & 0.09 & 0.18 \\
\hline Pregnant woman aq & $37.27 \pm$ & $37.37 \pm$ & $37.27 \pm 0.03$ & $37.03 \pm$ & $36.90 \pm$ & $36.80 \pm$ \\
& 0.13 & 0.12 & & 0.09 & 0.06 & 0.00 \\
\hline
\end{tabular}

T: time; Aq: Aqueous decocted; Het: Hydro-ethanolic macerated

Mean \pm Standard Error on Average $(\mathrm{M} \pm \mathrm{ESM})$

$\mathrm{P}<0.05$

The result is that the recipes result in a linear fall in the rectal temperatures of the Wistar rats. Compared to the negative control, we note that all the extracts contain anti-pyretic molecules. The aqueous decoction of the recipe of the child showed activity antipyretic significant comparable to that of aspirin (reference molecule). Malaria being a disease febrile, these extracts are indicated in case of malaria but also during other febrile diseases.

Antiplasmodial activity:-

Aqueous decoction of the recipes of child and pregnant woman were used during the antiplasmodial test on clinical isolates (ex vivo) and reference strain K1 (in vitro) of Plasmodium falciparum. Table 6 shows the different IC50 obtained. 
Tableau 6:-IC50 $(\mu \mathrm{g} / \mathrm{mL})$ of the extracts against Plasmodium falciparum

\begin{tabular}{|l|c|c|}
\hline & Child & Pregnant woman \\
\hline Clinical isolate 1 & $\mathbf{1 2 . 8 8} \pm \mathbf{1 . 6 9}$ & $26.46 \pm 3.20$ \\
\hline Clinical isolate 2 & $18.81 \pm 2.31$ & $30.75 \pm 2.27$ \\
\hline Clinical isolate 3 & $22.37 \pm 1.41$ & $39.01 \pm 1.10$ \\
\hline K1 strain & $\mathbf{1 0 . 2 1} \pm \mathbf{1 . 8 2}$ & N D \\
\hline
\end{tabular}

The child's recipe has a promising effect on clinical isolate $1(12.88 \pm 1.69 \mu \mathrm{g} / \mathrm{mL})$ and $\mathrm{K} 1$ strain $(10.21 \mu \mathrm{g} / \mathrm{mL})$ of Plasmodium falciparum with IC50 values below $15 \mu \mathrm{g} / \mathrm{mL}$. We observe moderate anti-plasmodial activity with the recipe of the pregnant woman. These results provide scientific proof of the efficacy of the combinations of plants traditionally used by the lacustrine population of southern Benin in the treatment of malaria. This justifies the enthusiasm of the population for these anti-malaria recipes accessible at lower cost.

\section{Hemolytic test «in vitro:-}

The table below shows the percentage of hemolysis of aqueous decoction of the plant combinations studied.

Tableau 7:-Percentage of hemolysis of both recipes

\begin{tabular}{|l|c|}
\hline & Percentage of hemolysis (\%) \\
\hline Child & 1.57 \\
\hline Pregnant woman & 0.89 \\
\hline
\end{tabular}

A hemolytic power is defined if the percentage of hemolysis is greater than $5 \%$. The recipe of the child has the highest hemolytic activity, however it does not exceed $1.57 \%$. We can therefore conclude that the extracts are not hemolytic and are potential candidates for antiplasmodial molecules research.

\section{Conclusion:-}

This study aims to contribute to the fight against malaria through the study of toxicity and anti-radical, anti-pyretic, anti-plasmodial and hemolytic activities of two combinations of plants used to treat malaria in children and pregnant women in a lacustrine villages in southern Benin. At the end of this study, it should be noted that the aqueous decocted of the child's recipe is not-toxic, not-haemolytic, with promising anti-plasmodial, anti-pyretic and antiradical activities. This head combination of plants is a potential source of anti-radical, anti-plasmodial and antipyretic molecules. Clinical studies will allow its use in pharmaceutical and para-pharmaceutical industries.

\section{References:-}

1. Corral M. G., Leroux J., Stubbs K. A., \& Mylne J. S., (2017). Herbicidal properties of antimalarial drugs. Scientific Reports, 7: 458-471

2. Dawet A., Yakubu D. P., Wannang N. N. \& Mwansat G. S., (2014). In vivo antimalarial activity of stem bark of dry zone cedar Pseudocedrela kotschyi (Meliaceae) in mice. European Journal of Medicinal Plants 4(3): 342352.

3. http://www.who.int/malaria/publications/world-malaria-report-2018/report/fr/

4. Ministère de la santé, (2013). Annuaire des statistiques sanitaires 2012. République du Bénin,115.

5. Devender N., Gunjan S., Tripathi R. \& Tripathi R. P., (2017). Synthesis and antiplasmodial activity of novel indoleamide derivatives bearing sulfonamide and triazole pharmacophores. European Journal of Medicinal Chemistry 131: 171-184

6. Békro Y. A., Békro J. A. M., Boua B. B. \& Tra F. H., (2010). Expérience du Centre Anti-Poison et de Pharmacovigilance du Maroc (1980-2008). Toxicologie Maroc. 5: 5-8.

7. Bekro Y. A., Bekro J. A. M., Boua B. B., Tra B. F. H. \& Ehile E. E., (2007). Etude ethnobotanique et screening phytochimique de Caesalpinia benthamiana (Baill.) Herend. Et Zarucchi (Caesalpiniaceae). Re. Sci. Nat, 4 (2): 217-225

8. Dohou N., Yamni K., Tahrouch S., Hassani L. M. I., Bodoc A. \& Gmira N., (2003). Screening phytochimique d'une endemique Ibero-marocain, Thymelaea lytroides. Bulletin de la Société de pharmacie de Bordeaux; 61-78

9. Bruneton J., (1999). Pharmacognosie-Phytochimie Plantes médicinales, 3 éd Tech et documentation éditions médicales.

10. Soro T. Y., Traore F., Datte J. Y. \& Nene-Bi, (2009). Activité anti-pyrétique de l'extrait aqueux de Ximenia americana. Phytotherapie, 297-303 
11. Siddhuraju P., Mohan P. S. \& Becker K., (2002). Studies on the antioxidant activity of Indian Laburnum (Cassia fistula L.), a preliminary assessment of crude extracts from stem bark, leaves, flowers and fruit pulp. Journal of Food Chemistry 79 (1): 61-67

12. Agbangnan P., Tachon C., Bonin C., Chrostowka A., Fouquet E. \& Sohounhloue D. C. K.,(2012). Phytochemical study of a tinctorial plant of Benin traditional pharmacopoeia: The red sorghum (Sorghum caudatum) of Benin. Scientific Study \& Research, 13 (2):121-135

13. Xu B. J. \& Chang S. K. C., (2007). A comparative study on phenolic profiles and antioxidant activities of legumes as affected by extraction solvents. Journal of Food Science, 72 (2): 160-161

14. Brand-Willams W., Cuvelier M. E. \& Beret C., (1995). Use of a free radical method to evaluate antioxidant activity, Lebensm. Wiss.U. Technol, 25-30.

15. Bakoma B., Berké B., Eklu-Gadegbeku K., Agbonon A., Aklikokou K., Gbeassor M., Creppy E. E. \& Moore N., (2013). Acute and sub-chronic (28 days) oral toxicity evaluation of hydroethanolic extract of Bridelia ferruginea Benth root bark in male rodent animals. Food and Chemical Toxicology 52:176-179

16. Dosseh K., Kpatcha T., Adjrah Y., Idoh K., Agbonon A. \& Gbéassor M., (2014). Antiinflammatory effect of Byrsocarpus coccineus schum. and thonn. (Connaraceae) root. World Journal of Pharmaceutical Research 3 (3): 3585-3598.

17. Trager W. \& Jensen J. B., (1976). Human malaria parasites in continuous culture. Science193:673-675.

18. Smilkstein M., Sriwilaijaroen N., Kelly J. X., Wilairat P. \& Riscoe M., (2004). Simple and inexpensive fluorescence-based technique for high-throughput antimalarial drug screening. Antimicrobial Agents and Chemotherapy, 48:1803-1806.

19. Basco L. K., Heseltine E., \& World Health Organization, (2007). Field application of in vitro assays for the sensitivity of human malaria parasites to antimalarial drugs.

20. Akala H. M., Eyase F. L., Cheruiyot A. R., Omondi A. A., Ogutu B. R., Waters N. C., Johnson J. D., Polhemus M. E., Schnabel D. C. \& Walsh D.S., (2011). Anti-malarial drug sensitivity profile of western Kenya Plasmodium falciparum field isolates determined by a SYBR green I in vitro assay, and molecular analysis. American Journal of Tropical Medicine and Hygiene, 85:34-41.

21. Tuo K., (2015). Criblage phytochimique, activité antioxydante et anti-plasmodiale in vitro de cinq plantes utilisées traditionnellement en Côte d'Ivoire contre le paludisme. Thèse présentée pour l'obtention du titre de docteur de l’Université Félix Houphouët-Boigny, 200.

22. Adebayo J. O. \& Krettli A. U., (2011). Potential antimalarials from Nigerian plants: a review. Journal of Ethnopharmacology 133: 289-302

23. Singh S. V., Manhas A., Singh S. P., Mishra S., Tiwari N., Kumar P., Shanker K., Srivastava K., Sashidhara K. V. \& Pal A., (2017). A phenolic glycoside from Flacourtia indica induces heme mediated oxidative stress in Plasmodium falciparum and attenuates malaria pathogenesis in mice. Phytomedicine 30, 1.

24. Zhou B., Wu Y., Dalal S., Merino E. F., Liu Q. F., Xu C. H., Yuan T., Ding J., Kingston D. G. I., Cassera M. B. \& Yue J. M., (2017). Nanomolar antimalarial agents against chloroquine-resistant Plasmodium falciparum from Medicinal Plants and their structure-activity relationships. Journal of Natural Products ; 80:1.

25. Penchev P., Angelov G. \& Condoret J. S., (2010). Extraction des agents antioxydants (aciderosmarinique) à partir de la mélisse (Melissa officinalis L.). Revue de génie industriel 5: 115-123

26. Jokić S., Velić D., Bilić M., Bucić-Kojić A., Plan inić M. \& Tomas S., (2010). Modelling of the process of solid-liquid extraction of total polyphenols from Soybeans. Journal of Food Science, 28:206-212.

27. Hodge A. c. \& Sterner J. H, (1980). Determination of substances acute toxicity by LD50.American Industrial Hygien Association 10:93.

28. Hilaly J. E., Israili Z. H. \& Lyouss B., (2004). Acute and chronic toxicological studies of Ajuva iva in experimental animals. Journal of Ethnopharmacology 91: 43-50. 